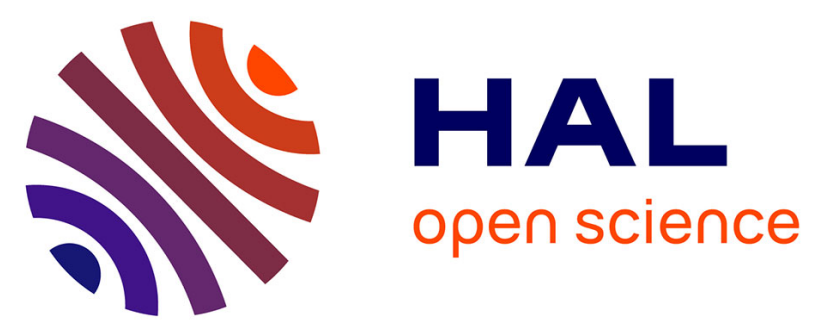

\title{
A three-layer model for buckling of a human aortic segment under specific flow-pressure conditions
}

Marco Amabili, Kostas Karazis, Rosaire Mongrain, Michael Païdoussis, Raymond Cartier

\section{- To cite this version:}

Marco Amabili, Kostas Karazis, Rosaire Mongrain, Michael Païdoussis, Raymond Cartier. A threelayer model for buckling of a human aortic segment under specific flow-pressure conditions. International Journal for Numerical Methods in Biomedical Engineering, 2012, 10.1002/cnm.1484 . hal01302308

\section{HAL Id: hal-01302308 \\ https://hal.science/hal-01302308}

Submitted on 14 Apr 2016

HAL is a multi-disciplinary open access archive for the deposit and dissemination of scientific research documents, whether they are published or not. The documents may come from teaching and research institutions in France or abroad, or from public or private research centers.
L'archive ouverte pluridisciplinaire HAL, est destinée au dépôt et à la diffusion de documents scientifiques de niveau recherche, publiés ou non, émanant des établissements d'enseignement et de recherche français ou étrangers, des laboratoires publics ou privés.

\section{다(1)(2)}

Distributed under a Creative Commons Attribution - ShareAlikel 4.0 International 


\title{
A three-layer model for buckling of a human aortic segment under specific flow-pressure conditions
}

\author{
M. Amabili, K. Karazis, R. Mongrain, M. Païdoussis \\ Department of Mechanical Engineering, McGill University, Canada \\ R. Cartier \\ Montreal Heart Institute Research Centre, Canada
}

\begin{abstract}
Human aortas are subjected to large mechanical stresses because of blood flow pressurization and through contact with the surrounding tissue. It is essential that the aorta does not lose stability by buckling with deformation of the cross-section (shell-like buckling) (i) for its proper functioning to ensure blood flow and (ii) to avoid high stresses in the aortic wall. A numerical bifurcation analysis employs a refined reducedorder model to investigate the stability of a straight aorta segment conveying blood flow. The structural model assumes a nonlinear cylindrical orthotropic laminated composite shell composed of three layers representing the tunica intima, media and adventitia. Residual stresses because of pressurization are evaluated and included in the model. The fluid is formulated using a hybrid model that contains the unsteady effects obtained from linear potential flow theory and the steady viscous effects obtained from the time-averaged Navier-Stokes equations. The aortic segment loses stability by divergence with deformation of the crosssection at a critical flow velocity for a given static pressure, exhibiting a strong subcritical behaviour with partial or total collapse of the inner wall. Preliminary results suggest directions for further study in relation to the appearance and growth of dissection in the aorta.
\end{abstract}

\section{INTRODUCTION}

A great deal of work has been accomplished on the collapse and flutter of collapsible tubes modelling blood flow in veins, pulmonary passages and the urethra; refer to the reviews by [1-3], and papers by [4-7] for instance. At this point, the mechanisms leading to static collapse and flutter of such systems may be said to be well understood, though the means of prediction are not yet fully satisfactorily explained, mainly because of the large deformations involved.

In this respect, arterial dynamics should, in principle, be easier to handle. However, conventionally, arteries have been considered capable of withstanding large deformations without adverse effects. One of the most catastrophic cardiovascular diseases is associated with the dissection of the aorta by a sudden rupture of the internal layer, tunica intima, of the aortic wall [8-10]. It is assumed that, if the mechanical stresses applied to the aorta wall exceed some critical value combined with certain medical conditions, rupture occurs, propagating in the axial direction following a spiroidal path and splitting the inner two-thirds and outer one-third of the media layer apart [11,12]. According to recent studies, aortic wall dissection occurs for 2.6-3.5 per 100,000 person-years, with a mortality increase of up to $2 \%$ per hour after symptoms have been detected $[13,14]$. Even though 
the general assumption is that high mechanical stresses causing inner tissue rupture in the aorta are a significant factor, the underlying mechanism of aorta dissection is poorly understood. The main reason for that is that direct measurements of the risk factors in vivo are not feasible $[15,16]$. In addition, simulation of the aorta, which is a complex part of the circulatory system that changes dramatically in shape and size according to the systolic and diastolic pressure field, and in material properties because of mechanical stresses and age, is extremely difficult to perform [17].

The arterial wall consists of four major components: muscles, elastin, collagen and fibroblasts. Muscles are an active component of the aortic wall affecting also the geometry and elastic properties of the aorta. Elastin is a rubber-like material made from a protein in a polymerized form, which is elastic and can sustain large stresses and strains. Collagen fibers provide the required arterial wall strength and they are responsible for the nonlinear elastic behaviour of the wall for higher strain values. For lower strains, the fibers are folded and do not contribute significantly to the elastic properties of the aorta. Fibroblasts have an inherent gel-like viscous behaviour and their contribution to wall elasticity is usually neglected [18]. The histological analysis of the aortic segment provides three distinct layers called tunicae: tunica intima, tunica media and tunica adventitia, shown in Figure 1. It has been recorded that the stiffness of the intima is much larger than that of the media and adventitia [15]. Thus, the inner part of the aorta is stiffer than the outer layer and deforms much less during the systolic-diastolic cycle [19]. If a vascular disease is present, such as atherosclerosis, the mechanical properties of the affected layers of the aortic wall change significantly from those of the healthy aorta. In our analysis, the elastic properties of the aortic wall for each tunica layer in the circumferential and axial directions are derived by making use of the experiments in [20]. In

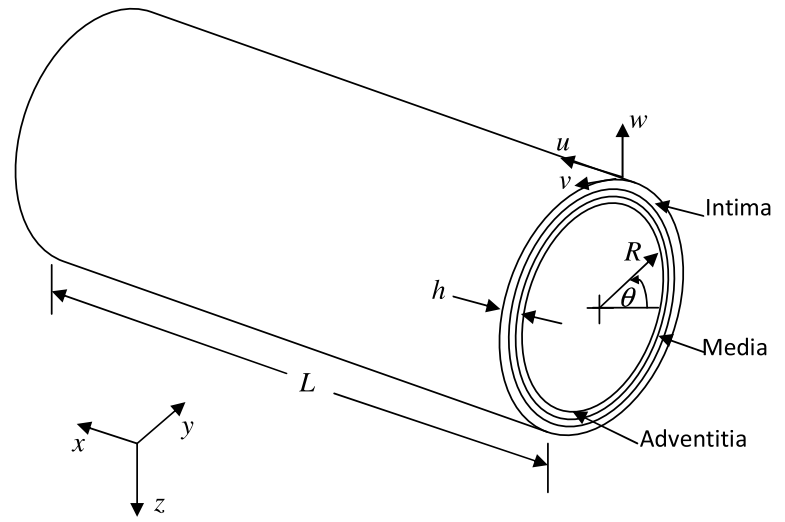

(a)

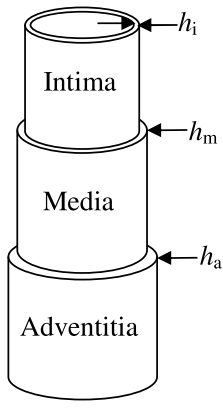

(b)

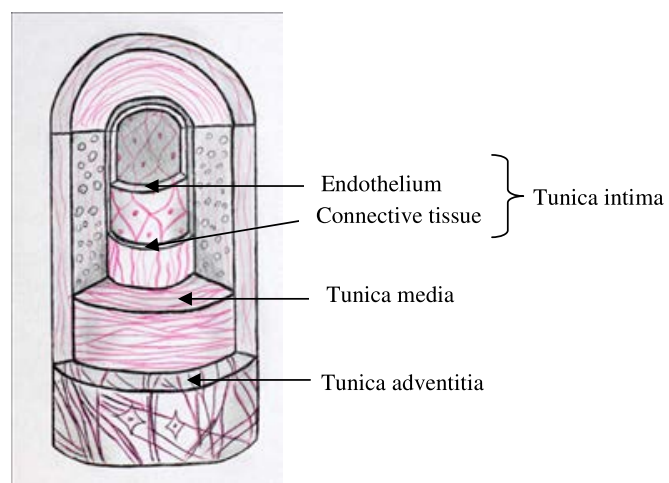

(c)

Figure 1. Aorta segment configuration. (a) A circular cylindrical shell segment used in the simulation; (b) the three layers used in the modeling of the aorta; (c) dissection of the aortic wall (courtesy of Ms. Olga German). 
literature, there are also averaged values for the stiffness of the aortic wall, or for each layer treated as an isotropic material, obtained from experiments, indicating the effect of disease on the stiffness of the aorta [16, 21, 22, 24-29, 32]. The difference in the values for Young's modulus of the aorta found in the literature is explained by investigating the methodology used in these studies to obtain the data, age of the individual, location and pathology of the individual specimen.

Different numerical models have been used to simulate healthy aortic walls or aortas under pathological conditions [30]. In recent models, material anisotropy, hyperelasticity of the aorta wall and residual stresses are treated in the analysis $[23,31,33,34]$. It has been observed that residual stresses present in the uncut configuration of the aorta play a significant role on the stability of the aortic wall. If the arterial wall is cut transversely to the axial direction, during an experimental analysis, the wall shrinks in the axial direction, while it springs open if it is cut in the radial direction [19]. The effect of different opening angles, because of the presence of residual stresses of each arterial layer, was further investigated in [35], where beam-like buckling of arteries was also investigated. Furthermore, it has been shown that axial residual stresses in an artery reduce the critical internal pressure for buckling of the aorta, which may lead to arterial tortuosity [36].

With respect to the interaction of the aorta wall with blood flow, there has been recent progress in the development of fluid-solid and fluid-structure interaction models to simulate the aorta under different loading conditions. Usually, the ALE approach has been employed resulting in a large number of DOF numerical models. Recent mathematical models use arterial growth and remodelling techniques to capture the wall stresses accurately. It is widely accepted that new aorta-wall models must be developed to account, among other physiological parameters, also for the effect of dynamic collagen production for the development of the strong collagen fiber found in the arterial walls [37]. In addition, pulsatile flow models along with newly developed experimental methods have been used to investigate the location of maximum stress in the systolic-diastolic cycle [38,39]. Interesting reviews on the mechanical models used for the arterial wall displacement are given in $[18,37]$.

The present paper proposes to study the possibility of buckling with cross-section deformation (i.e. shell-like buckling, different from beam-type buckling) of a straight thoracic aortic segment for specific pressure and flow conditions by means of a geometrically nonlinear model, thus following in the path of the studies of $[4,40]$ for collapsible tubes. This study relates the nonlinear buckling of the aorta and the consequent appearance of high stress regions at the inner layer of the aorta wall that may be responsible for the initiation of dissection. The aortic segment is modelled as a three-layered orthotropic laminate composite shell by means of Sanders-Koiter nonlinear shell theory, while the fluid is modelled by a Newtonian inviscid flow theory but taking into account steady viscous stresses via the time-averaged Navier-Stokes equations. A linear analysis is performed first to obtain the most appropriate generalized coordinates to be used in the nonlinear reduced-order model. These generalized coordinates are used in the expansion of the aorta wall displacement in the nonlinear analysis. The nonlinear analysis is performed in two phases: (i) initially a radial pressurization is progressively applied to obtain the nonlinear deformation and the initial stresses in the aortic wall; (ii) once the desired pressure is reached, the blood flow velocity is increased and used as bifurcation parameter to study the buckling and post-buckling of the aorta. In this second phase, the material properties of the three layers stretched in the circumferential direction are used. In fact, as shown in Appendix B, the stress-strain experimental curves for the human aorta can be fitted by two lines, representing an initial stiffness and an increased stiffness for greatly stretched wall.

As a first attempt to describe the nonlinear behaviour of the aortic segment, a quasi-steady approach is taken, in which the flow is not pulsatile but steady. Specifically, the most critical combinations of pressure and flow during a heart beating period are considered for possible triggering of buckling. Shell-like buckling occurs for a short period of time; it is almost an instantaneous phenomenon because (i) the pressure build-up upstream forces the wall of the aorta to open back to its original shape, and (ii) the pressure and flow conditions change with time.

\section{SHELL AND FLUID-STRUCTURE INTERACTION MODELS}

The introduction of bifurcation theory in the nonlinear analysis of shells conveying fluid has produced new theoretical findings in the recent past. In particular, [41] showed for the first time that 
such systems lose stability by divergence, exhibiting a strongly subcritical nonlinear behaviour (i.e. buckling is obtained for smaller flow velocity than the bifurcation point). This was confirmed experimentally [42] and studied further in [43]. Here, the word 'bifurcation' signals the qualitative change of a mathematical solution and the generation of new solution branches that describe the new behaviour of the system. The point of occurrence of this qualitative change is called bifurcation point. A significant advantage of using bifurcation theory compared with other numerical techniques for fluid-structure interaction is that bifurcation analysis identifies all possible stable and unstable branches of the solutions for a range of the critical parameter employed (i.e. the flow velocity or the transmural pressure in the present analysis) vis-à-vis results obtained from finite element (FEA) models, which tend to produce results for a specific values of the critical parameters. Evidently, bifurcation analysis can be efficiently performed only by using reduced-order models (i.e. with a relatively small number of DOFs), which also produce accurate results considerably faster than finite element models.

The model of the aortic segment consists of a circular cylindrical shell of length $L$, mean internal radius $R$, and thicknesses $h^{\mathrm{i}}, h^{\mathrm{m}}$, and $h^{\mathrm{a}}$ of each one of the three tunica layers, as shown in Figure 1(b). The origin of the cylindrical coordinate system, $(O ; x, \theta, r)$, is positioned at the centre of one end of the shell, as shown in Figure 1(a). The shell is assumed to be made of anisotropic elastic material composed of three layers stacked together at various orientations according to experimental observations [20]. The displacements of the shell middle surface are denoted by $u, v$ and $w$, in the axial, circumferential and radial directions, respectively; $w$ is taken positive outward. The actual geometry of an aorta displays deviations from an ideal circular cylindrical shell. Even though this effect is not investigated in the present study, geometric imperfections can nevertheless be investigated by using the approach introduced by some of the present authors [43], which has the advantage of avoiding further complication of the present model.

The strain vector $\boldsymbol{\varepsilon}_{x \theta r}$ of the aortic segment, modelled as a circular cylindrical shell, in the global shell coordinates is given by

$$
\boldsymbol{\varepsilon}_{x \theta r}=\mathbf{N}(u, v, w),
$$

where $\mathbf{N}$ is a nonlinear vector differential function of the shell displacements $u, v, w$ of the middle surface of the shell, obtained by using the Sanders-Koiter nonlinear shell theory [44]. The straindisplacement relationships and changes in the curvature and torsion for an arbitrary point associated with the middle surface of each layer of the cylindrical shell for the Sanders-Koiter nonlinear shell theory are given in Appendix A.

The stress-strain relations for the $k$-th orthotropic layer of the shell, in the material principal coordinates $(O ; 1,2, r)$ under the hypothesis that $\sigma_{r}=0$, are given by [44-46]

$$
\sigma_{12 r}{ }^{(k)}=\mathbf{C}^{(k)} \boldsymbol{\varepsilon}_{12 r},
$$

where $\sigma_{12 r}^{(k)}$ is the stress vector in the $k$-th layer and $\varepsilon_{12 r}$ is the strain vector, both in the material principal coordinates, and $\mathbf{C}^{(k)}$ is the matrix containing the material properties of the $k$-th transversely isotropic layer. In particular, the elements of the $\mathbf{C}^{(k)}$ matrix are

$$
\begin{aligned}
& c_{11}=\frac{E_{1}}{1-v_{12} \nu_{21}}, \quad c_{12}=c_{21}=\frac{E_{2} \nu_{12}}{1-v_{12} \nu_{21}}, \\
& c_{22}=\frac{E_{2}}{1-v_{12} \nu_{21}}, \quad c_{33}=G_{12}, \quad c_{13}=c_{23}=c_{31}=c_{32}=0,
\end{aligned}
$$

where $E$ is Young's modulus, $v$ is the Poisson's ratio and $G_{12}$ is the shear modulus in 1-2 directions; in Equation (3) the superscript $(k)$ has been dropped for simplicity, but all the material properties must be referred to the $k$-th layer. Equation (2) can be transformed to global shell coordinates $(O ; x, \theta, r)$ by the following vectorial equation:

$$
\boldsymbol{\sigma}_{x \theta r}^{(k)}=[Q]^{(k)} \boldsymbol{\varepsilon}_{x \theta r},
$$


where $\sigma_{x \theta r}^{(k)}$ and $\varepsilon_{x \theta r}$ are now expressed in the global shell coordinates and $[Q]^{(k)}$ is the matrix of the material properties of the $k$-th layer. The stresses and strains in the material coordinate system are related to the corresponding components in the global shell coordinate system by [45]

$$
\sigma_{12 r}=\mathbf{T}_{1} \sigma_{x \theta r}, \quad \varepsilon_{12 r}=\mathbf{T}_{2} \boldsymbol{\varepsilon}_{x \theta r} .
$$

The coordinate transformation matrices $\mathbf{T}_{1}$ and $\mathbf{T}_{2}$ contain trigonometric functions of the angle $\theta^{(k)}$ between the global shell axis $x$ and the material principal coordinate 1 [45]. It can be shown that

$$
\left(\mathbf{T}_{1}^{-1}\right)^{\mathrm{T}}=\mathbf{T}_{2}
$$

Therefore, the matrix $[Q]^{(k)}$ in Equation (4) can be given by

$$
[Q]^{(k)}=\left[\mathbf{T}_{2}^{-\mathrm{T}} \mathbf{C} \mathbf{T}_{2}\right]^{(k)} .
$$

A variational approach is employed to obtain the equations of motion for the aortic segment. Therefore, expressions for the potential and kinetic energies of the shell for each lamina and the fluid (blood) are coupled in the Lagrange equation. Specifically, the expression for the kinetic energy is given by

$$
T_{\mathrm{S}}=\frac{1}{2} \sum_{k=1}^{K} \rho_{S}^{(k)} \int_{0}^{L} \int_{0}^{2 \pi} \int_{h^{(k-1)}}^{h^{(k)}}\left\{\dot{u}^{2}+\dot{v}^{2}+\dot{w}^{2}\right\}(1+z / R) \mathrm{d} x R \mathrm{~d} \theta \mathrm{d} z
$$

where $K=3$ is the total number of layers in the laminated aortic wall, $\left(h^{(k-1)}, h^{(k)}\right)$ are the $z$ coordinates of the $k$-th layer, $\rho_{S}^{(k)}$ is the mass density of the $k$-th layer of the shell, and the overdot denotes a time derivative. The potential energy of the aortic wall $U_{S}$ is made up of two contributions: the elastic strain energy $U_{\text {shell }}$ of the aortic segment and the potential energy $U_{\text {spring }}$ stored by the axial and rotational distributed springs at the aorta ends that represent the boundary conditions of the aortic segment; therefore,

$$
U_{S}=U_{\text {shell }}+U_{\text {spring }}
$$

The elastic strain energy $U_{\text {shell }}$ of a laminated circular cylindrical shell is given in [44]

$$
U_{\text {shell }}=\frac{1}{2} \sum_{k=1}^{K} \rho_{S}^{(k)} \int_{0}^{L} \int_{0}^{2 \pi} \int_{h^{(k-1)}}^{h^{(k)}}\left(\sigma_{x}^{(k)} \varepsilon_{x}+\sigma_{\theta}^{(k)} \varepsilon_{\theta}+\tau_{x \theta}^{(k)} \gamma_{x \theta}\right)(1+z / R) \mathrm{d} x R \mathrm{~d} \theta \mathrm{d} z,
$$

where $\sigma_{x}, \sigma_{y}$ and $\tau_{x y}$ are the stresses related to the strains $\varepsilon_{x}, \varepsilon_{y}$ and $\gamma_{x y}$ [44].

The potential energy stored by the axial and rotational springs at the shell ends is given by

$$
U_{\text {spring }}=\frac{1}{2} \int_{0}^{2 \pi}\left\{k_{\mathrm{a}}\left[(u)_{x=0}\right]^{2}+k_{\mathrm{a}}\left[(u)_{x=L}\right]^{2}+k_{\mathrm{r}}\left[\left(\frac{\partial w}{\partial x}\right)_{x=0}\right]^{2}+k_{\mathrm{r}}\left[\left(\frac{\partial w}{\partial x}\right)_{x=L}\right]^{2}\right\} d \theta .
$$

The following boundary conditions, with flexible constraints to simulate connection with the remaining tissue, are imposed at the shell ends:

$$
v=w=w_{0}=0, \quad N_{x}=-k_{\mathrm{a}} u, \quad M_{x}=-k_{\mathrm{r}}(\partial w / \partial x) \quad \text { at } x=0, L,
$$

where $N_{x}$ is the axial stress resultant per unit length, $M_{x}$ the bending moment per unit length, $k_{\mathrm{a}}$ and $k_{\mathrm{r}}$ are the stiffnesses per unit length of the axial and rotational constraints, respectively. The shell 
displacements are discretized by using trigonometric expansions that identically satisfy the geometric boundary conditions; these trigonometric functions are the eigenmodes of the linear problem in case of simply supported boundary conditions. In particular,

$$
\begin{aligned}
u(x, \theta, t)= & \sum_{m=1}^{8}\left[u_{m, n, \mathrm{c}}(t) \cos (n \theta)+u_{m, n, \mathrm{~s}}(t) \sin (n \theta)\right] \cos \left(\lambda_{m} x\right) \\
& +\sum_{m=1}^{3} u_{m, 2 n, \mathrm{c}}(t) \cos (2 n \theta) \cos \left(\lambda_{m} x\right)+\sum_{m=1}^{11} u_{m, 0}(t) \cos \left(\lambda_{m} x\right), \\
v(x, \theta, t)= & \sum_{m=1}^{8}\left[v_{m, n, \mathrm{c}}(t) \sin (n \theta)+v_{m, j, \mathrm{~s}}(t) \cos (n \theta)\right] \sin \left(\lambda_{m} x\right) \\
& +\sum_{m=1}^{6} v_{m, 2 n, \mathrm{c}}(t) \sin (2 n \theta) \sin \left(\lambda_{m} x\right) \\
w(x, \theta, t)= & \sum_{m=1}^{8}\left[w_{m, n, c}(t) \cos (n \theta)+w_{m, n, s}(t) \sin (n \theta)\right] \sin \left(\lambda_{m} x\right) \\
& +\sum_{m=1}^{11} w_{m, 0}(t) \sin \left(\lambda_{m} x\right),
\end{aligned}
$$

where $n$ is the number of circumferential waves, $m$ is the number of longitudinal half-waves, $\lambda_{m}=m \pi / L$, and $t$ is the time; $u_{m, j}(t), v_{m, j}(t)$ and $w_{m, j}(t)$ are the generalized coordinates [44]. A nonlinear term $\hat{u}(t)$ is added to the expansion of $u$, Equation (13a), to satisfy exactly the boundary condition (12d); this term is obtained as a function of the generalized coordinates [43]. The advantage of the global discretization with the generalized coordinates used in Equations (13a)-(13c) is that a relatively small number of DOFs, in this case 89 that can be reduced to 55 by selecting terms with last subscript $c$ because of symmetry considerations, is used to build a reduced-order model.

\subsection{Fluid-structure interaction and solution method}

Under normal conditions the flow in the aorta is neither laminar nor fully turbulent. In vivo results indicate that the flow is either smooth laminar or irregular that eventually becomes turbulent [47]. Numerous studies have assumed a transition turbulent or fully turbulent flow profile to investigate aortic dissection, aortic aneurysms and other arterial configurations and diseases [11,48-54].

In this analysis, the flow conditions are assumed to be associated with physiological conditions or pathological diseases (e.g. aortic stenosis, hypertension or atherosclerosis) upstream that induce a turbulent flow in the aortic segment. The fluid-structure interaction model obtains the unsteady fluid motion by potential flow theory and the steady viscous effects for turbulent flow by the timeaverage Navier-Stokes equations. The unsteady viscous effects have been found to give a very small contribution to the stability of shells conveying a fully developed turbulent flow [3].

An unsteady perturbation potential $\Phi$ is introduced that satisfies the Laplace equation $[43,55,56]$

$$
\nabla^{2} \Phi=\frac{\partial^{2} \Phi}{\partial x^{2}}+\frac{\partial^{2} \Phi}{\partial r^{2}}+\frac{1}{r} \frac{\partial \Phi}{\partial r}+\frac{1}{r^{2}} \frac{\partial^{2} \Phi}{\partial \theta^{2}}=0
$$

If no cavitation occurs at the blood-aorta interface, the boundary condition expressing the contact between the shell wall and the flow is given by

$$
\left(\frac{\partial \Phi}{\partial r}\right)_{r=R}=\left(\frac{\partial w}{\partial t}+U \frac{\partial w}{\partial x}\right)
$$

where $U$ is the mean blood flow velocity. 
Equation (14) and the Laplace equation are satisfied if the solution for the velocity potential is given by

$$
\Phi=\sum_{m=1}^{M} \sum_{n=0}^{N} \frac{L}{m \pi} \frac{\mathrm{I}_{n}(m \pi r / L)}{\mathrm{I}_{n}^{\prime}(m \pi R / L)}\left(\frac{\partial w_{m, n}}{\partial t}+U \frac{\partial w_{m, n}}{\partial x}\right),
$$

where $\mathrm{I}_{n}$ is the modified Bessel function of the first kind of order $n$, and $I_{n}^{\prime}$ is the derivative of $\mathrm{I}_{n}$ with respect to its argument. Therefore, the perturbation pressure at the aorta wall interface is found to be given by

$$
p=-\rho_{\mathrm{F}} \sum_{m=1}^{M} \sum_{n=0}^{N} \frac{L}{m \pi} \frac{\mathrm{I}_{n}(m \pi R / L)}{\mathrm{I}_{n}^{\prime}(m \pi R / L)}\left(\frac{\partial}{\partial t}+U \frac{\partial}{\partial x}\right)^{2} w_{m, n},
$$

where $\rho_{\mathrm{F}}$ is the fluid density.

Green's theorem is used to obtain the total energy associated with the flow, which can be divided into three terms: kinetic energy, potential energy and gyroscopic energy, as given in the expression below

$$
E_{\mathrm{F}}=T_{\mathrm{F}}+E_{\mathrm{G}}-V_{\mathrm{F}}
$$

the first and second of the three terms on the right-hand side can be identified as the kinetic and gyroscopic energy, respectively; an opposite sign is introduced for the potential energy $V_{\mathrm{F}}$, for convenience. The kinetic energy $T_{\mathrm{F}}$ of the fluid is given by

$$
T_{\mathrm{F}}=\frac{1}{2} \rho_{\mathrm{F}} \sum_{m=1}^{M} \sum_{n=0}^{N} \int_{0}^{2 \pi} \int_{0}^{L} \frac{L}{m \pi} \frac{\mathrm{I}_{n}(m \pi R / L)}{\mathrm{I}_{n}^{\prime}(m \pi R / L)} \dot{w}_{m, n}^{2} \mathrm{~d} x R \mathrm{~d} \theta .
$$

It is interesting to observe that $T_{\mathrm{F}}$ does not depend on the mean flow velocity $U$. The potential energy $V_{\mathrm{F}}$ is given by

$$
V_{\mathrm{F}}=-\frac{1}{2} \rho_{\mathrm{F}} \sum_{m=1}^{M} \sum_{n=0}^{N} \int_{0}^{2 \pi} \int_{0}^{L} \frac{L}{m \pi} \frac{\mathrm{I}_{n}(m \pi R / L)}{\mathrm{I}_{n}^{\prime}(m \pi R / L)} U^{2}\left(\frac{\partial w_{m, n}}{\partial x}\right) \mathrm{d} x R \mathrm{~d} \theta .
$$

Equation (20) shows that $V_{\mathrm{F}}$ is negative, that is, the stiffness of the system is a decreasing function of $U$. This explains the shell instability at sufficiently high values of $U$.

The gyroscopic energy $E_{\mathrm{G}}$ associated with the perturbation potential is

$$
E_{\mathrm{G}}=\frac{1}{2} \rho_{\mathrm{F}} \sum_{m=1}^{M} \sum_{l=1}^{M} \sum_{n=0}^{N} \sum_{k=0}^{N} \int_{0}^{2 \pi} \int_{0}^{L} \frac{U L}{m \pi} \frac{\mathrm{I}_{n}(m \pi R / L)}{\mathrm{I}_{n}^{\prime}(m \pi R / L)}\left(\dot{w}_{m, n} \frac{\partial w_{l, k}}{\partial x}+\dot{w}_{l, k} \frac{\partial w_{m, n}}{\partial x}\right) \mathrm{d} x R \mathrm{~d} \theta
$$

The time-averaged Navier-Stokes equations are employed to calculate the steady viscous effects assuming that the flow is turbulent. The result is a variable mean transmural pressure $\Delta P_{\mathrm{tm}}$ along the shell because of the pressure drop and a frictional traction on the internal wall in the axial direction. A detailed description of the solution for the time-averaged Navier-Stokes equations used here is given in $[43,57]$. This type of hybrid model is particularly efficient from the computational point of view. In particular, the pressure drop in the aortic segment is given by

$$
P_{x=0}-P_{x=L}=f \frac{\rho_{\mathrm{F}}}{4 R} L U^{2} .
$$


The friction factor $f$ in Equation (22) can be calculated by using the experimental Colebrook equation. The constant axial friction traction force per unit area is

$$
\tau_{x}=f \rho_{\mathrm{F}} U^{2} / 8
$$

\subsection{Lagrange equations of motion}

The final Lagrange equations of motion are written as follows:

$$
\frac{d}{d t}\left[\frac{\partial\left(T_{\mathrm{S}}+T_{\mathrm{F}}\right)}{\partial \dot{q}_{j}}\right]-2 \frac{\partial E_{\mathrm{G}}}{\partial q_{j}}+\frac{\partial\left(U_{\mathrm{S}}+V_{\mathrm{F}}\right)}{\partial q_{j}}=Q_{j}, \quad j=1, \ldots, N_{\mathrm{T}},
$$

where $T_{\mathrm{S}}$ and $T_{\mathrm{F}}$ are the kinetic energy of the shell and the fluid, respectively, $U_{\mathrm{S}}$ and $V_{\mathrm{F}}$ are the potential energy of the shell and the fluid, respectively, $E_{\mathrm{G}}$ is the gyroscopic energy associated with the flow, and $Q_{j}$ are the generalized external forces, including the transmural pressure $\Delta P_{\mathrm{tm}}$, which is affected by the pressure drop, the axial friction forces and damping:

$$
Q_{j}=-\frac{\partial F}{\partial \dot{q}_{j}}+\frac{\partial W}{\partial q_{j}},
$$

where

$$
W=\int_{0}^{2 \pi} \int_{0}^{L}\left(\Delta P_{\mathrm{tm}} w+\tau_{x} u\right) \mathrm{d} x R \mathrm{~d} \theta, \quad F=\frac{1}{2} c \int_{0}^{2 \pi} \int_{0}^{L}\left(\dot{u}^{2}+\dot{v}^{2}+\dot{w}^{2}\right) \mathrm{d} x R \mathrm{~d} \theta,
$$

and $c$ is the viscous damping coefficient, which does not play a role because the problem considered has a static buckling solution. The number of DOFs is $N_{\mathrm{T}}$. The vector $\mathbf{q}$ of the generalized coordinates $u_{m, n}(t), v_{m, n}(t), w_{m, n}(t)$ is introduced and the final equations of motion for the aortic wall are given in matrix form in the following expression:

$$
\mathbf{M} \ddot{\mathbf{q}}+\mathbf{C} \dot{\mathbf{q}}+\left[\mathbf{K}+\mathbf{N}_{\mathbf{2}} \mathbf{q}+\mathbf{N}_{\mathbf{3}}(\mathbf{q}, \mathbf{q})\right] \mathbf{q}=\mathbf{Q},
$$

where $\mathbf{M}$ is the mass matrix (including the effect of the fluid), $\mathbf{C}$ the damping matrix, $\mathbf{K}$ the linear stiffness matrix, $\mathbf{N}_{2}$ a matrix that gives the quadratic nonlinear terms related to the displacements, $\mathbf{N}_{3}$ a matrix that involves the cubic nonlinear terms associated with the displacements, and $\mathbf{Q}$ the vector of the external loads, which includes pressurization of the artery in the radial direction and axial friction forces. The total number of DOFs used in the present model is $N_{\mathrm{T}}=55$. The present reduced-order model has been validated in the past for isotropic shells by comparing it to experimental results [43] for aluminum and plastic shells conveying water.

\section{NUMERICAL MODEL}

The cylindrical straight thoracic aortic segment is modelled using the nonlinear shell theory presented in Section 2. The resulting 55 second-order nonlinear ordinary differential equations (27) are divided by the modal mass and further recast into 110 first-order ordinary differential equations. Once nondimensionalized, the resulting ordinary differential equations are studied via a continuation method to perform a bifurcation analysis. Here, the nonlinear analysis of the aortic segment subjected to internal blood flow is divided into two steps. First, the pressure is increased at zero flow velocity up to reach the desired value; this gives the wall deformation and initial stresses. In fact, residual stresses have a very significant influence on arterial mechanical behaviour. In this analysis the elastic material properties of the unstretched layers have to be used initially. In the second step, the flow velocity is used as bifurcation parameter to study the buckling and post-buckling of the aorta, by using the material properties of the stretched, in the circumferential direction, aorta layers. The software AUTO [58], utilizing pseudo-arclength 
continuation and collocation methods for continuation of the solution, bifurcation analysis and branch switching, is used to solve numerically the nonlinear equations.

It must be pointed out that the total number of DOFs used in this study is much smaller compared with the number of DOFs used in finite element analysis to resolve an aortic wall segment, in some cases even compared with the number of DOFs needed for only one element used with finite element analysis modelling.

Several models have assumed an isotropic aortic wall segment as a first approximation in their analysis $[11,15,59]$. In our analysis, the aorta wall is simulated with three orthotropic layers representing the tunica intima, media and adventitia. It is well known that the measured total thickness of the human aorta depends on the individual's health, age, geographical location and the individual's pathological profile. In general, the average thickness of the aorta wall varies from $h=0.7$ to 2.7 $\mathrm{mm}$. In our analysis the thickness of each layer of the aortic wall was based on the results, given in [20].

The human aorta stiffness is a complex function that depends at least on the individual, geographic location, age, overall health condition, mechanical stress, temperature and blood viscosity. Regardless of the nonlinear behaviour of the whole tissue as shown in the in vivo results a number of previous studies assumed a linear elastic behaviour for the physiological range of arterial wall deformation $[11,60]$. However, there is a large difference in the modulus of elasticity between the circumferential and axial directions for each layer, and among the three layers. In our analysis the values of Young's modulus for each orthotropic layer of the aorta were calculated using the results from uniaxial extension tests given in [20]. The experimental stress-strain curves presented in [20] for each one of the three layers in tension and compression for both axial and circumferential directions, one of them being reproduced in Appendix B, indicated that there are transition points at which the layers become much stiffer. Therefore, initially the stiffness of each layer lies on the practically constant slope segment of the stress-strain curve. At a specific strain, the slope suddenly increases and thereafter it remains quite constant. This type of behaviour has been modelled by using initially the smallest of the two Young's moduli for each layer and in each direction at the beginning of the nonlinear analysis, when the shell is pressurized. When the shell reaches the appropriate deformation, the value of Young's modulus is updated to the higher value. This happens only in the circumferential direction of the shell, which is stretched by pressurization.

In all numerical experiments the mass density of the aortic segment was assumed to be 1200 $\mathrm{kg} / \mathrm{m}^{3}$ and the Poisson's ratio $v=0.49$ [29]. Buckling occurs in shell-like mode with circumferential wavenumber $n=2$. The fluid in our analysis is considered to be Newtonian with a density of $1050 \mathrm{~kg} / \mathrm{m}^{3}$ and a kinematic viscosity of $4 \times 10^{-6} \mathrm{~m}^{2} / \mathrm{s}$ (4 centi-stokes). A Newtonian approximation has been considered to be acceptable for calculations related to large arteries like the aorta $[16,61]$ Johnston et al., 2006. In addition, the flow is considered to be fully-developed turbulent, which is a valid assumption at sufficiently high flow velocities and for cases where arterial wall disease is present [37,51] (for these simulations, the range of interest of the Reynolds number is from $4 \times 10^{3}$ to $7 \times 10^{3}$ ). The roughness of the arterial wall used in the Colebrook equation (steady viscous effects) was set equal to $2 \times 10^{-2} \mathrm{~mm}$, which corresponds to the thickness of the endothelial cells lining the wall $[62,63]$.

The flexible boundary conditions at the shell ends were assumed to simulate relatively stiff axial constraints, enabling simulation of connective tissue stresses at the outer ends of the aorta, but allowing rotations in the inner end of the aorta [37]. In most of the calculations, the spring constraints were set to $k_{\mathrm{a}}=1 \times 10^{3} \mathrm{~N} / \mathrm{m}^{2}$ and $k_{\mathrm{r}}=10^{2} \mathrm{~N} / \mathrm{rad}$.

The value of the transmural pressure $\Delta P_{\mathrm{tm}}$ simulated different aortic pressure loadings ranging from $3 \mathrm{kPa}$ to $13 \mathrm{kPa}$. This range for the static differential pressure is in agreement with the measured pressure of the aorta observed in the literature $[11,64]$. In general, the total pressure measured in the aorta varies between 9 to $14 \mathrm{kPa}$, with the dynamic pressure being proportional to the square of the velocity. In the present model both the flow and the pressure are assumed to be constant, although it is well known that they are both time-periodic functions with a phase delay between them [64]. Here, it is assumed that the buckling instability, which is the target of this study, could be triggered by an unfavourable combination of these two parameters, irrespective of pulsation, which 
is a reasonable assumption. This is a first attempt to characterize the nonlinear buckling of an aortic segment for specific flow conditions, acknowledging the fact that a pulsatile flow model must be used to accurately define these flow conditions for instability to occur.

\section{NUMERICAL RESULTS}

\subsection{Nonlinear buckling of a straight anisotropic aortic segment conveying blood}

The present model uses a mean aorta radius $R$ of $15.75 \mathrm{~mm}$, which is close to the experimental data by [65]. The length of the simulated aorta segment is $126 \mathrm{~mm}$ [66]. Table I summarizes the geometry and material properties used in this simulation. The flow velocity was increased gradually from 0 to $5 \mathrm{~m} / \mathrm{s}$ (high flow velocities have been measured in sport medicine, e.g., see Ref. [67]) with a static transmural pressure $\Delta P_{\mathrm{tm}}=5 \mathrm{kPa}$ and associated residual stresses. Here it can be specified that the transmural pressure (also called free-stream static pressure) is the pressure difference between the inner and outer shell surface in presence of flow, while the total pressure is the stagnation pressure that also takes into account the kinetic energy of the fluid converted into pressure. Figure 2 shows

Table I. Geometry and material properties of the aortic segment. $E$ is Young's modulus in the axial and circumferential directions associated with strains obtained in the second phase of the analysis after pressurization. Material properties and thickness of the three layers have been extracted by using the experimental data by [20], as discussed in Appendix B.

\begin{tabular}{lcc}
\hline Length $L(\mathrm{~m})$ & Mean radius $R(\mathrm{~m})$ & Density $\rho_{s}\left(\mathrm{~kg} / \mathrm{m}^{3}\right)$ \\
\hline 0.126 & 0.01575 & 1200 \\
Tunica Intima & $E_{\text {Axial }}^{\mathrm{i}}(\mathrm{kPa})$ & $E_{\text {Circumferential }}^{\mathrm{i}}(\mathrm{kPa})$ \\
Thickness $h_{i}(\mathrm{~m})$ & 360.5 & \\
0.00033 & & $E_{\text {Circumferential }}^{\mathrm{m}}(\mathrm{kPa})$ \\
Tunica Media & $E_{\text {Axial }}^{\mathrm{m}}(\mathrm{kPa})$ & 107.9 \\
Thickness $h_{m}(\mathrm{~m})$ & 72.8 & $E_{\text {Circumferential }}^{\mathrm{a}}(\mathrm{kPa})$ \\
0.00132 & $E_{\text {Axial }}^{\mathrm{a}}(\mathrm{kPa})$ & 25.6 \\
Tunica Adventitia & 26.7 & \\
Thickness $h_{a}(\mathrm{~m})$ & &
\end{tabular}

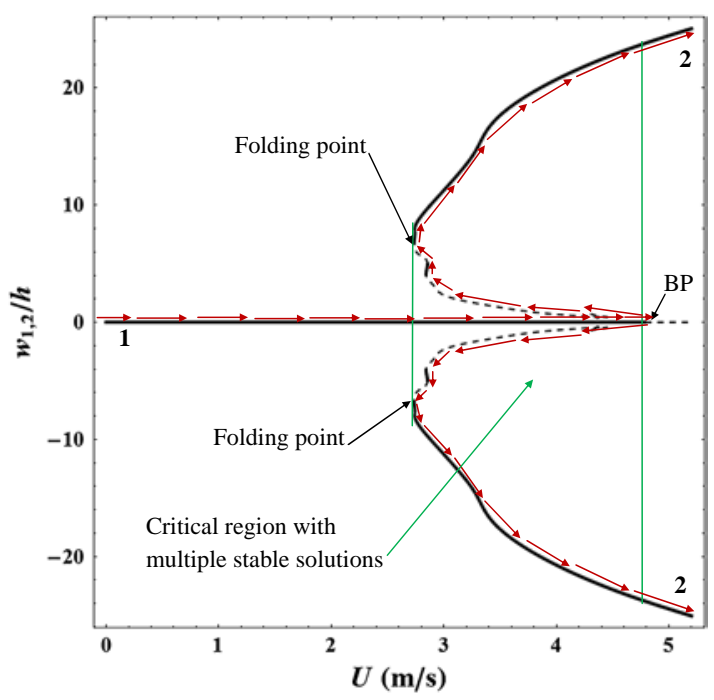

Figure 2. Static solutions of the aortic segment versus blood velocity with static trasmural pressure of $5 \mathrm{kPa}$. The vertical axis shows the radial displacement divided by the wall thickness.

- - - - -, unstable solutions; BP denotes the bifurcation point predicted by linear theory. 
the resulting bifurcation diagram as a plot of the maximum radial deformation of the shell divided by the aorta thickness versus flow velocity for the main generalized coordinate $w_{1,2}$. The shape of the shell-like buckled aortic segment is shown in Figure 3 and displays deformation with circumferential wavenumber $n=2$. The generalized coordinate chosen to be plotted in Figure 2 is the one with the largest contribution in the shell deformation. The deformation of the aortic segment follows branch 1 of the solution with zero amplitude (meaning that the aortic segment maintains its original circular shape along this solution branch). However, when the blood flow velocity reaches $4.78 \mathrm{~m} / \mathrm{s}$, the aortic segment loses stability by static divergence, that is, buckling (this is the point of the linear onset of instability) generating the new solution branches 2. Divergence (buckling) in this case means that a new static solution emerges, with a distinctive circumferential wavenumber of $n=2$ (the aorta wall moves inwards creating two lobes, thus $n=2$ ). Solution branch 2 is initially unstable (dotted lines) with its locus moving to the left; this behaviour is defined as 'subcritical'. The solution becomes stable for a short range of flow velocities from 2.841 to $2.855 \mathrm{~m} / \mathrm{s}$ as shown in Figure 2. Then it turns unstable again and it follows the subcritical unstable solution until it reaches the folding points at $U=2.73 \mathrm{~m} / \mathrm{s}$, whereupon branch 2 folds and becomes stable, losing again stability for a small range of blood flow velocity and restabilizing again while increasing in amplitude with increasing flow velocity.

These results indicate, for the first time in the literature of biomechanical vascular systems, that a straight aortic segment may lose stability by buckling because of blood flow and exhibit a highly subcritical nonlinear behaviour, such that there is a large range of flow velocities in which multiple stable configurations coexist for the specific flow and pressure conditions. This result means that, in this flow range $(2.73<U<4.78 \mathrm{~m} / \mathrm{s})$ - the subcritical range - the aortic segment may jump from one stable configuration to another (and vice versa), if enough perturbation is given to the system in the form of a flow spike, transmural pressure perturbation or external force (trauma case); this clearly results in increased mechanical stresses on the aortic wall. This also means that a large amplitude buckling may occur (i.e. the aorta wall may collapse with large enough deformation for inner-wall contact and complete folding or kinking of the aorta). This in turn may cause significant material damage (aorta wall dilation) in pathological situations, weakening transverse wall stiffness, leading to the initiation of an aneurysm or dissection (delamination of the wall layers). Furthermore, as the blood flow velocity increases or decreases in the diastolic-systolic cycle, it is evident that the deformation of the aortic segment may follow any of the stable branches, increasing or decreasing the mechanical stresses acting on the aortic wall, making it prone to failure because of microscopic fatigue [73]. Moreover, the results shown in Figure 2 fall in the acceptable limits for blood flow velocity and pressure values given in literature, with a maximum velocity peak around $2.5 \mathrm{~m} / \mathrm{s}$ in healthy conditions [67] and to more than $5 \mathrm{~m} / \mathrm{s}$ in cases of aortic stenosis [69]. Furthermore, in this

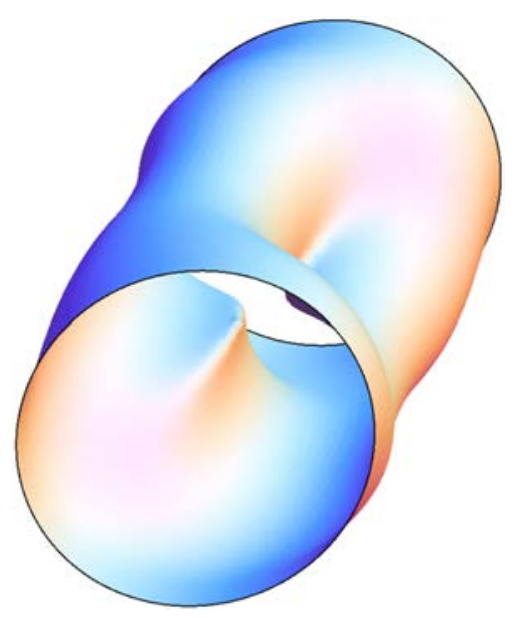

Figure 3. Shape of the buckled aorta as a combination of a total blood pressure of $7 \mathrm{kPa}$ and a critical blood flow velocity of $2.276 \mathrm{~m} / \mathrm{s}$. 


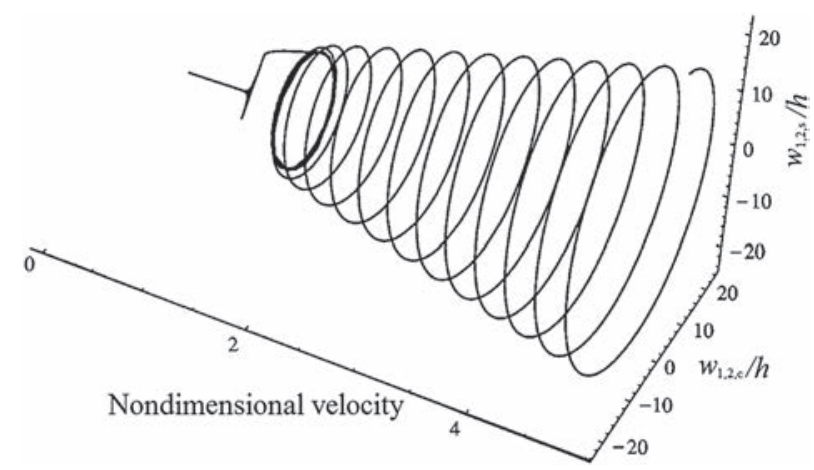

Figure 4. The helicoidal path followed by the aorta after collapse (taken from [41]) coherent with the aortic wall rupture path observed in dissections.

study the length of the aortic wall segment used is shorter than the full length found in humans. It has been shown in [70] that shorter cylindrical vessels lose stability at higher flow velocities therefore, it is expected that if a longer aortic wall is used in the simulations, a smaller critical flow velocity could have been attained.

Figure 3 shows the shape of the buckled aortic segment for blood flow velocity $U=2.276 \mathrm{~m} / \mathrm{s}$ with a total pressure of $7 \mathrm{kPa}$. It is evident that, at the neighbourhood of maximum deflection, large stresses are generated because of the high curvature. In many cases, buckling may induce contact of the inner aortic wall.

The result shown in Figure 2 is a simplified two-dimensional representation of the actual aortic segment behaviour. In fact, the buckling could occur in any direction because of the axial symmetry of the system. Once buckling has been initiated at a specific angle $\theta$, it propagates (i.e. increases in amplitude) as the flow velocity increases, following a spiroidal (helicoidal) path, as illustrated in Figure 4. The solution branches shown in Figure 2 represent the generatrix of the axisymmetric surface on which the helicoidal path in Figure 4 unfolds. Interestingly, these results are in qualitative agreement with clinical observations regarding the propagation of dissection in human aortas [68].

\subsection{Effect of different stiffnesses of an aortic segment}

The effect of altering Young's modulus in the longitudinal and/or circumferential direction (or both) of the aortic wall on the overall stability of the aortic segment conveying blood is further investigated in this section. The analysis of the aortic segment remains the same as in the previous section; however, in the second step of the nonlinear analysis, the values of the Young's moduli varied up to $\pm 40 \%$ from the values used in the previous simulations. It is a well-known fact that diseased arteries exhibit different elastic properties than healthy ones especially at higher pressure loads [19]. Therefore, the variation in the elasticity of the aortic segment, in any direction, is an attempt to capture some of the mechanical property effects of an aorta on the nonlinear stability at nominal blood flow velocity values.

Figure 5 shows the response of the aortic wall segment subjected to increasing blood flow velocity for different stiffness variations. In all cases the aortic segment loses stability by buckling, experiencing a hysteretic response similar to the one described in the previous section. The results in Figure 5(a), indicate that, when Young's modulus is varied by $\pm 40 \%$ in all tunica layers and directions, the onset of instability along with the folding points is shifted, depending on the value of Young's modulus. For a reduced value by $40 \%$ in both axial and circumferential directions the pitchfork bifurcation and folding points are shifted to the left of the original curve as shown in Figure 5(a). Similarly, for a stiffer wall the stability is shifted to the right of the original curve. In addition, a higher stiffness produces a slightly more complicated result with additional stable solutions within the hysteretic region. In Figure 5(b) a comparison among the original model and models with different Young's modulus in the circumferential direction. In particular, the circumferential Young's modulus of each layer was reduced twice; once by $40 \%$ and in the second simulation 


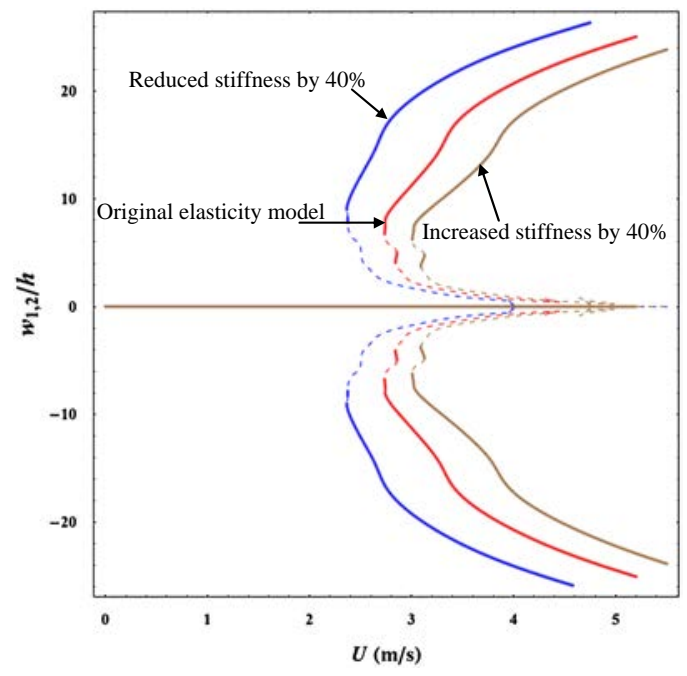

(a)

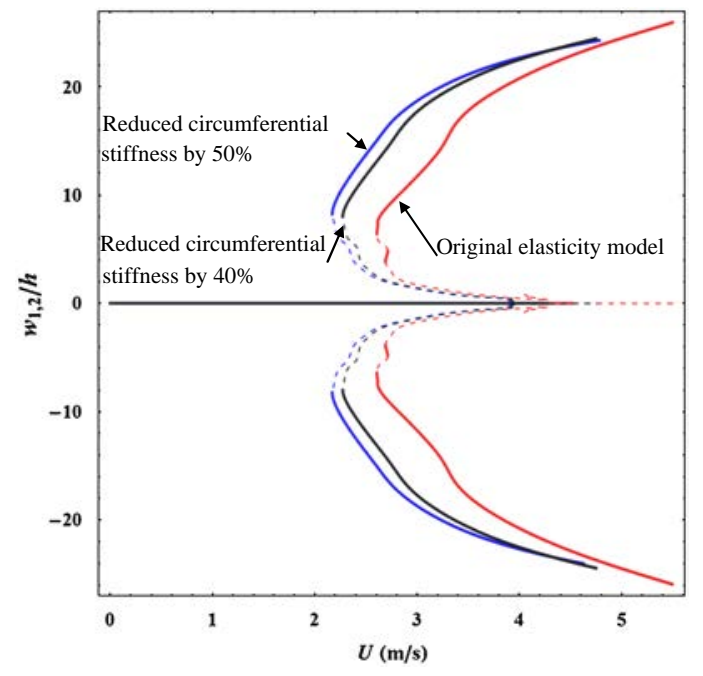

(b)

Figure 5. Nonlinear behaviour of the aortic segment for different Young's moduli of the tunica layers for a static transmural pressure of $5 \mathrm{kPa}$. (a) Results with $\pm 40 \%$ Young's moduli in all layers and directions; (b) results with different circumferential Young's modulus in all layers.

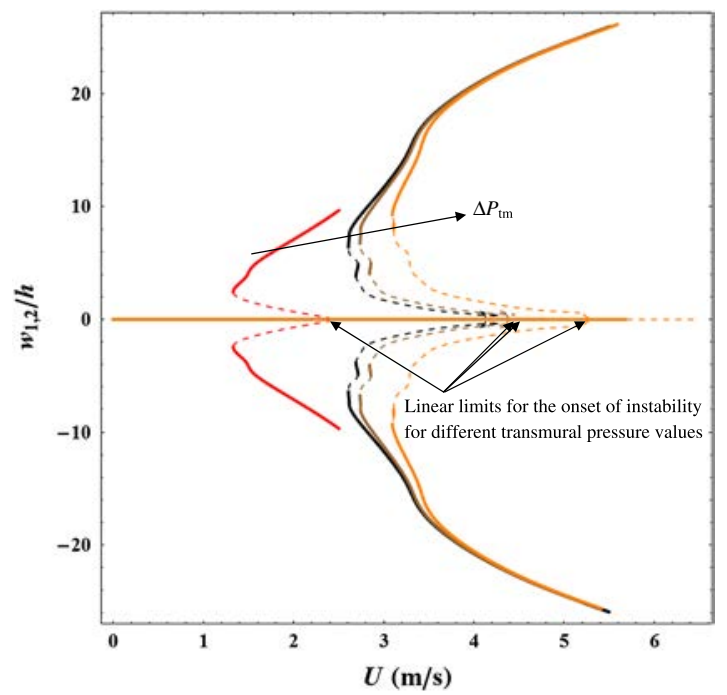

Figure 6. Static solutions of the aortic segment versus blood velocity for different static trasmural pressures $\Delta P_{\mathrm{tm}}=0 \mathrm{kPa}, 4 \mathrm{kPa}, 5 \mathrm{kPa}$, and $9 \mathrm{kPa}$.

by $50 \%$ of their original values in Table I. Pressurization of the aortic segment was set to $4 \mathrm{kPa}$ in addition to the dynamic pressurization because of the blood flow. Results indicate that lowering Young's modulus in the circumferential direction drastically reduces the folding point of the solution branch.

\subsection{Nonlinear behaviour of an aortic segment for different $\Delta P_{\mathrm{tm}}$ values}

The effect of transmural pressure $\Delta P_{\mathrm{tm}}$ on aortic wall deformation has been the topic of numerous studies attempting to associate it with the appearance and growth of aneurysms and dissection because of the increased mechanical stresses on the surface of the aorta $[59,71,72]$. In our analysis it was decided to investigate the effect of different values of transmural pressure on the aortic segment stability. Figure 6 shows the bifurcation diagram of the three-layered aortic segment subjected to 
different transmural pressures and increasing blood flow. The results indicate that the presence of an increased transmural pressure delays the onset of instability predicted by linear theory. In addition, an increased transmural pressure makes the hysteretic behaviour and subcritical response of the aorta more pronounced, producing larger aortic wall deformation amplitudes. If the blood flow rate falls within this important subcritical range, there is a high probability that a simple perturbation may cause the system to be attracted to the stable large-deformation solution, with potentially total collapse of the aortic segment with full contact of the inner aortic wall; this in turn would constrict the blood flow, until the cross-section opens up again and is thus susceptible to buckling once again.

\section{CONCLUSIONS AND DISCUSSION}

We have presented the theoretical framework to model nonlinear shell-like buckling of straight human aortic segments because of blood flow. Large arteries like the aorta are continuously subjected to significant mechanical loads from internal blood flow and surrounding tissue and muscle, making them prone to small-scale oscillations and probable wall thinning which, in the presence of a pathological disease, might lead to aorta dissection. The structural model was developed using the Sanders-Koiter nonlinear shell theory for laminated composite materials representing the three tunica layers present in the aorta wall.

The results show that flow-induced buckling (or even collapse) of the aortic segment is possible under specific flow and pressure conditions. Furthermore, under these critical conditions a highly subcritical nonlinear behaviour arises (i.e. buckling at much smaller flow than the classical linear buckling limit), with multiple stable solutions (zero deformation shape, buckled aorta, or total collapse) coexisting for a wide range of blood flow velocities. One could speculate that even a healthy person performing routine exercises might be exposed to the right combination of blood flow and pressure to trigger loss of stability by buckling [67]. Furthermore, the high curvature associated with buckling induces high stress regions which, combined with the fatigue cycles of the heart beats, could contribute in initiating rupture of the inner aortic layer, that is, the tunica intima, and hence dissection. In fact, buckling introduces bending of the wall that generates much higher stress in the intima layer as a consequence of the much larger stiffness. As shown in Figure 3, the path of the bifurcated solution for the aortic segment model developed in this study follows a spiroidal (helicoidal) route, similar to the spiroidal path observed when dissection occurs in human aortas.

A stiffer material delays the onset of instability, but exhibits a similarly strong subcritical response and will have higher stresses because of the higher Young's modulus. Increasing the transmural pressure renders the system more stable with respect to the onset of buckling. However, the system exhibits a pronounced subcritical behaviour. It is here conjectured that the pressurizationdepressurization of the aorta because of the systolic-diastolic cycle, or a strenuous exercise regime, which leads to a constant oscillation of the aorta, when coupled with cardiovascular disease or other pathological problems, might induce material deterioration and thus the appearance and growth of aneurysms or dissection.

Concerning the limitations of the present work, we should mention that the aortic segment considered in this study is assumed to be a circular cylindrical shell, with no account taken of geometrical imperfections and curvature effects. Even though recent studies for shells with imperfections have produced similar qualitative results as in the present study, a more sophisticated model that includes these imperfections should be considered in due course. In addition, the effect of pressurization could be studied more accurately when a pulsatile time-dependent blood flow model is used. A more accurate model should include the viscoelastic and hyperelastic properties of human tissue to describe the effect of hysteresis on the nonlinear behaviour of the aorta, and a non-Newtonian fluid model.

Nevertheless, this study presents for the first time the possibility of subcritical buckling (collapse) of aortic segments, which could be of crucial importance in human health. In addition, for the first time, a global analysis tool, namely bifurcation analysis, has been used to obtain all stable and unstable solutions associated with aortas conveying blood flow, thus allowing for the full set of results for a range of flow velocities to be investigated. 
The strain-displacement relationships and changes in the curvature and torsion for a generic point of the shell at distance $z$ from the middle surface are given by

$$
\varepsilon_{x}=\varepsilon_{x, 0}+z \kappa_{x}, \quad \varepsilon_{\theta}=\varepsilon_{\theta, 0}+z \kappa_{\theta}, \quad \gamma_{x \theta}=\gamma_{x \theta, 0}+z \kappa_{x \theta}
$$

The middle surface strain-displacement relationships, changes in curvature and torsion are

$$
\begin{gathered}
\varepsilon_{x, 0}=\frac{\partial u}{\partial x}+\frac{1}{2}\left(\frac{\partial u}{\partial x}\right)^{2}+\frac{1}{8}\left(\frac{\partial v}{\partial x}-\frac{\partial u}{R \partial \theta}\right)^{2}+\frac{\partial w}{\partial x} \frac{\partial w_{0}}{\partial x} \\
\varepsilon_{\theta, 0}=\frac{\partial v}{R \partial \theta}+\frac{w}{R}+\frac{1}{2}\left(\frac{\partial w}{R \partial \theta}-\frac{v}{R}\right)^{2}+\frac{1}{8}\left(\frac{\partial u}{R \partial \theta}-\frac{\partial v}{\partial x}\right)^{2}+\frac{\partial w_{0}}{R \partial \theta}\left(\frac{\partial w}{R \partial \theta}-\frac{v}{R}\right), \\
\gamma_{x \theta, 0}=\frac{\partial v}{\partial x}+\frac{\partial u}{R \partial \theta}+\frac{\partial w}{\partial x}\left(\frac{\partial w}{R \partial \theta}-\frac{v}{R}\right)+\frac{\partial w_{0}}{\partial x}\left(\frac{\partial w}{R \partial \theta}-\frac{v}{R}\right)+\frac{\partial w}{\partial x} \frac{\partial w_{0}}{R \partial \theta} \\
\kappa_{x}=-\frac{\partial^{2} w}{\partial x^{2}} \\
\kappa_{\theta}=-\frac{\partial^{2} w}{R^{2} \partial \theta^{2}}+\frac{\partial v}{R^{2} \partial \theta} \\
\kappa_{x \theta}=-2 \frac{\partial^{2} w}{R \partial x \partial \theta}+\frac{1}{2 R}\left(3 \frac{\partial v}{\partial x}-\frac{\partial u}{R \partial \theta}\right)
\end{gathered}
$$

The effect of radial geometrical imperfections, denoted by $w_{0}$ in the strain-displacement equations above, is included.

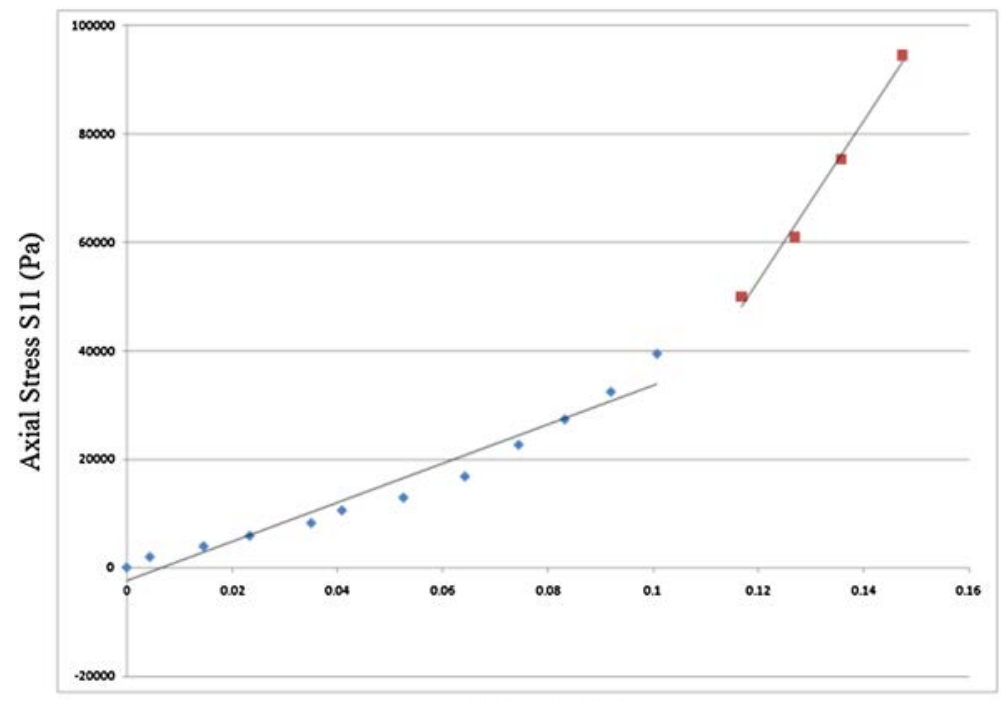

Axial Strain E11

Figure B.1. Stress-strain curve for the Intima layer in the axial direction as discussed in [38]. Loading configuration. 


\section{APPENDIX B. STRESS-STRAIN CURVES FROM IN VIVO MEASUREMENT OF THE AORTA}

The stress-strain curves used in the present study were estimated using the results obtained by [20] from a human female cadaver ( 80 years old) with a congestive cardiomyopathy disease. Figure B.1 presents the stress-strain curve for the intima layer in the axial direction in loading configuration as discussed in [20]. The data are interpolated with two lines with different slopes: the first one fitting the data for smaller strains and the other fitting data for higher strains. The deviation from the fitting lines is modest. Similar curves from Ref. [20] have been fitted to obtain the elasticity parameters for the three layers in both circumferential and axial directions.

\section{ACKNOWLEDGEMENTS}

The authors would like to thank NSERC Discovery Grant program, and the first author Canada Research Chair and Canada Foundation of Innovation (LOF) program of Canada, for their financial support.

\section{REFERENCES}

1. Bertram CD. The dynamics of collapsible tubes, 1995.

2. Kamm RD, Pedley TJ. Flow in collapsible tubes: A brief review. Journal of Biomechanical Engineering 1989; 111:177-179.

3. Païdoussis MP. Fluid-Structure Interactions: Slender Structures and Axial Flow, Vol. 2. Elsevier Academic Press: London, UK, 2004.

4. Heil M. The stability of cylindrical shells conveying viscous flow. Journal of Fluids and Structures 1996; 10:173-196.

5. Heil M. Stokes flow in collapsible tubes - Computation and experiment. Journal of Fluid Mechanics 1998; 353:285-312.

6. Luo XY, Pedley TJ. Flow and instability in collapsible tubes. ZAMM Zeitschrift für Angewandte Mathematik und Mechanik 1996; 76:37-40.

7. Pedley TJ, Luo XY. Modelling flow and oscillations in collapsible tubes. Theoretical and Computational Fluid Dynamics 1998; 10:277-294.

8. Barabas M, Gosselin G, Crépeau J, Petitclerc R, Cartier R, Théroux P. Left main stenting-as a bridge to surgery- for acute type A aortic dissection and anterior myocardial infarction. Catheterization and Cardiovascular Intervention 2000; 51:74-77.

9. Fuster V, Halperin JL. Aortic dissection: A medical perspective. Journal of Cardiac Surgery 1994; 9:713-728.

10. Roberts WC. Aortic dissection: Anatomy, consequences, and causes. American Heart Journal 1981; 101:195-214.

11. Khanafer K, Berguer R. Fluid-structure interaction analysis of turbulent pulsatile flow within a layered aortic wall as related to aortic dissection. Journal of Biomechanics 2009; 42:2642-2648.

12. Xavier R, Bourdeaud'hui A, Collet D, Laborde N, Baudet E. Traumatic rupture and aneurysm of the aortic isthmus: Late results of repair by direct suture. Annals of Vascular Surgery 1989; 3:47-51.

13. Chavanon O, Carrier M, Cartier R, Hébert Y, Pellerin M, Pagé P, Perrault LP. Increased incidence of acute ascending aortic dissection with off-pump aortocoronary bypass surgery. Annals of Thoracic Surgery 2001; 71:117-121.

14. Wang DS, Dake MD. Endovascular therapy for aortic dissection. In Thoracic Aortic Diseases, Rousseau H, Verhoye JP, Heautot JF (eds). Springer: New York, NY, 2006; 189-198.

15. Gao F, Watanabe M, Matsuazawa T. Stress analysis in a layered aortic arch model under pulsatile blood flow. BioMedical Engineering Online 2006a; 5:25.

16. Gao F, Guo Z, Sakamoto M, Matsuzawa T. Fluid-structure interaction within a layered aortic arch model. Journal of Biological Physics 2006b; 32:435-454.

17. Pemberton J, Sahn DJ. Imaging of the aorta. International Journal of Cardiology 2004; 97:53-60.

18. Kalita P, Schaefer R. Mechanical models of artery walls. Archives of Computational Methods in Engineering 2008; 15:1-36.

19. Balzani D. Simulation of deformation, damage and residual stresses in arterial walls. Advanced Engineering Materials 2008; 10:315-321.

20. Holzapfel GA. Determination of material models for arterial walls from uniaxial extension tests and histological structure. Journal of Theoretical Biology 2006; 238:290-302.

21. Brum J, Balay G, Bia D, Benech N, Ramos A, Armantano R, Negreira C. Improvement of Young modulus examination by ultrasound using static pressure steps. Physics Procedia 2010; 3:1087-1094.

22. Choudury N, Bouchot O, Rouleau L, Tremblay D, Cartier R, Mongrain R, Leask RL. Local mechanical and structural poperties of healthy and diseased human ascending aorta tissue. Cardiovascular Pathology 2009; 18:83-91.

23. Holzapfel GA, Sommer G, Regitnig P. Anisotropic mechanical properties of tissue components in human atherosclerotic plaques. Journal of Biomechanical Engineering 2004b; 126:657-665. 
24. Holzapfel GA, Sommer G, Gasser CT, Regitnig P. Determination of layer-specifc mechanical properties of human coronary arteries with nonatherosclerotic intimal thickening and related constitutive modeling. American Journal of Physiology - Heart and Circulatory Physiology 2005; 289:H2048-H2058.

25. Iliopoulos DC, Deveja RP, Kritharis EP, Perrea D, Sionis GD, Toutouzas K, Stefanidis C, Sokolis DP. Regional and directional variations in the mechanical properties of ascending thoracic aortic aneurysms. Medical Enginering \& Physics 2009; 31:1-9.

26. Loree HM, Grodzinsky AJ, Park SY, Gibson LJ, Lee RT. Static circumferential tangential modulus of human atherosclerotic tissue. Journal of Biomechanics 1994; 27:195-204.

27. Sommer G, Gasser TC, Regitnig P, Auer M, Holzapfel GA. Dissection properties of the human aortic media: An experimental study. Journal of Biomechanical Engineering 2008; 130:0210071-02100712.

28. Teng Z, Tang D, Zheng J, Woodard PK, Hoffman AH. An experimental study on the ultimate strength of the adventitia and media of human atherosclerotic carotid arteries in circumferential and axial directions. Journal of Biomechanics 2009; 42:2535-2539.

29. Tremblay D, Zigras T, Cartier R, Leduc L, Butany J, Mongrain R, Leask RL. A comparison of mechanical properties of materials used in aortic arch reconstruction. The Annals of Thoracic Surgery 2009; 88:1484-1491.

30. Holzapfel GA, Ogden RW. Constitutive modelling of arteries. Proceedings of the Royal Society A 2010a; 466:1551-1597.

31. Holzapfel GA, Gasser TC, Ogden RW. A new constitutive framework for arterial wall mechanics and a comparative study of material models. Journal of Elasticity 2000; 61:1-48.

32. Holzapfel G, Gasser TC, Ogden RW. Comparison of a multi-layer structural model for arterial walls with a Fung-type model, and issues of material stability. Journal of Biomechanical Engineering 2004a; 126:264-275.

33. Holzapfel GA, Ogden RW. Modelling the layer-specific three-dimensional residual stresses in arteries, with an application to the human aorta. Journal of the Royal Society Interface 2010b; 7:787-799.

34. Rodríguez JF, Ruiz C, Doblaré M, Holzapfel GA. Mechanical stresses in abdominal aortic aneurysms: Influence of diameter, asymmetry, and material anisotropy. Journal of Biomechanical Engineering 2008; 130: 0210231-02102310.

35. Goriely A, Vandiver R. On the mechanical stability of growing arteries. IMA Journal of Applied Mathematics 2010; 75:549-570.

36. Holzapfel GA, Sommer G, Auer M, Regitnig P, Ogden RW. Layer-specific 3D residual deformations of human aortas with non-atherosclerotic intimal thickening. Annals in Biomedical Engineering 2007; 35:530-545.

37. Taylor CA, Humphrey JD. Open problems in computational vascular biomechanics: Hemodynamics and arterial wall mechanics. Computational Methods in Applied Mechanics and Engineering 2009; 198:3514-3523.

38. Frydrychowicz A, Stalder AF, Russe MF, Bock J, Bauer S, Harloff A, Berger A, Langer M, Hennig J, Markl M. Three-dimensional analysis of segmental wall shear stress in the aorta by flow-sensitive four-dimensional MRI. Journal of Magnetic Resonance Imaging 2009; 30:77-84.

39. Wen C-Y, Yang A-S, Tseng L-Y, Chai J-W. Investigation of pulsatile flowfield in healthy thoracic aorta models. Annals of Biomedical Engineering 2010; 38:391-402.

40. Heil M, Pedley TJ. Large post-buckling deformations of cylindrical shells conveying viscous flow. Journal of Fluids and Structures 1996; 10:565-599.

41. Amabili M, Pellicano F, Païdoussis MP. Nonlinear dynamics and stability of circular cylindrical shells containing flowing fluid. Part I: Stability. Journal of Sound and Vibration 1999; 225:655-699.

42. Karagiozis KN, Païdoussis MP, Amabili M, Misra AK. Nonlinear stability of cylindrical shells subjected to axial flow: Theory and experiments. Journal of Sound and Vibration 2008; 309:637-676.

43. Amabili M, Karagiozis K, Païdoussis MP. Effect of geometric imperfections on nonlinear stability of circular cylindrical shells conveying fluid. International Journal of Non-Linear Mechanics 2009; 44:276-289.

44. Amabili M. Nonlinear Vibrations and Stability of Shells and Plates. Cambridge University Press: New York, USA, 2008.

45. Amabili M, Farhadi S. Shear deformable versus classical theories for nonlinear vibrations of rectangular isotropic and laminated composite plates. Journal of Sound and Vibration 2009; 320:649-667.

46. Reddy JN. Mechanics of Laminated Composite Plates and Shells: Theory and Analysis, Second Edition. CRC Press: Boca Raton, FL, USA, 2004.

47. Bluth EI, Murphey SM, Hollier LH, Sullivan MA. Color flow Doppler in the evaluation of aortic aneurysms. International Angiology 1990; 9:8-10.

48. Cheng Z, Tan FPP, Riga CV, Bicknell CD, Hamady MS, Gibbs RGJ, Wood NB, Xu XY. Analysis of flow patterns in a patient-specific aortic dissection model. Journal of Biomechanical Engineering 2010; 132:051007.

49. Egelhoff CJ, Budwig RS, Elger DF, Khraishi TA, Johanses KH. Model studies of the flow in abdominal aortic aneurysms during resting and exercise conditions. Journal of Biomechanics 1999; 32:1319-1329.

50. Jozwik K, Obidowski D. Numerical simulations of the blood flow through vertebral arteries. Journal of Biomechanics 2010; 43:177-185.

51. Khanafer KM, Bull JL, Berguer R. Fluid-structure interaction of turbulent pulsatile flow within a flexible wall axisymmetric aortic aneurysm model. European Journal of Mechanics B/Fluids 2009; 28:88-102.

52. Li JK-J. Laminar and turbulent flow in the mammalian aorta: Reynolds number. Journal of Theoretical Biology 1988; 135:409-414. 
53. Nerem RM, Seed WA, Wood NB. An experimental study of the velocity distribution and transition to turbulence in the aorta. Journal of Fluid Mechanics 1972; 52:137-160.

54. Paul MC, Molla MMd, Roditi G. Large-Eddy simulation of pulsatile blood flow. Medical Engineering \& Physics 2009; 31:153-159.

55. De Langre E, Ouvrard AE. Absolute and convective bending instabilities in fluid-conveying pipes. Journal of Fluids and Structures 1999; 13:663-680.

56. Païdoussis MP, Denise J-P. Flutter of thin shells conveying fluid. Journal of Sound and Vibration 1972; 20:9-26.

57. Païdoussis MP, Misra AK, Chan SP. Dynamics and stability of coaxial cylindrical shells conveying viscous fluid. Journal of Applied Mechanics 1985; 52:389-396.

58. Doedel EJ, Champneys AR, Fairgrieve TF, Kuznetsov YA, Sandstede B, Wang X. AUTO 97: Continuation and Bifurcation Software for Ordinary Differential Equations (with HomCont). Concordia University: Montreal, Canada, 1998.

59. Thubrikar MJ, Agali P, Robicsek F. Wall stress as a possible mechanism for the development of transverse intimal tears in aortic dissections. Journal of Medical Engineering \& Technology 1999; 23:127-134.

60. Ranga A, Mongrain R, Mendes Galaz R, Biadillah Y, Cartier R. Large-displacement 3D structural analysis of an aortic valve model with nonlinear material properties. Journal of Medical Engineering and Technology 2004; 28:95-103.

61. Johnston BM, Johnston PR, Corney S, Kilpatrick D. Non-Newtonian blood flow in human right coronary arteries: steady state simulations. Journal of Biomechanics 2004; 37:709-720.

62. Farcas MA, Rouleau L, Fraser R, Leask RL. The development of 3-D, in vitro, endothelial culture models for the study of coronary artery disease. Biomedical Engineering Online 2009; 8:30.

63. Liu SQ, Yen M, Fung YC. On measuring the third dimension of cultured endothelial cells in shear flow. Proceedings of the National Academy of the United States of America 1994; 91:8782-8786.

64. Mills C, Gabe I, Gault J, Mason D, Ross J, Braumwald E, Shillingford J. Pressure-flow relationships and vascular impedance in man. Cardiovascular Research 1970; 4:405-417.

65. Labrosse MR, Beller CJ, Mesana T, Veinot JP. Mechanical behavior of human aortas: Experiments, material constants and 3-D finite element modeling including residual stress. Journal of Biomechanics 2009; 42:996-1004.

66. Conrad MF, Crawford RS, Kwolek CJ, Brewster DC, Brady TJ, Cambria RP. Aortic remodeling after endovascular repair of acute complicated type B aortic dissection. Journal of Vascular Surgery 2009; 50:510-517.

67. Rowland TW, Grarrard M, Marwood S, Guerra ME, Roce D, Unnithan VB. Myocardial performance during progressive exercise in athletic adolescent males. Medicine \& Science in Sports \& Exercise 2009; 41:1721-1728.

68. Novelline RA, Rhea JT, Rao PM, Stuk JL. Helical CT in emergency radiology. Radiology 1999; 213:321-339.

69. Takeda S, Rimington H, Chambers J. Prediction of symptom-onset in aortic stenosis: a comparison of pressure drop/flow slope and haemodynamic measures at rest. International Journal of Cardiology 2001; 81:131-137.

70. Karagiozis KN, Païdoussis MP, Amabili M. Effect of geometry on the stability of cylindrical clamped shells subjected to internal fluid flow. Computers \&amp; Structures 2007; 85:645-659.

71. De Putter S, Wolters BJBM, Rutten MCM, Breeuwer M, Gerritsen FA, van de Vosse FN. Patient-specific initial wall stress in abdominal aortic aneurysms with a backward incremental method. Journal of Biomechanics 2007; 40:1081-1090.

72. Raghavan ML, Vorp DA. Toward a biomechanical tool to evaluate rupture potential of abdominal aortic aneurysm: identification of a finite strain constitutive model and evaluation of its applicability. Journal of Biomechanics 2000; 33:475-482.

73. Johnston BM, Johnston PR, Corney S, Kilpatrick D. Non-Newtonian blood flow in human right coronary arteries: Transient simulations. Journal of Biomechanics 2006; 39:1116-1128.

74. Volokh KY, Vorp DA. A model of growth and rupture of abdominal aortic aneurysm. Journal of Biomechanics 2008; 41:1015-1021. 